\title{
Elimination of fibrinogen from synovial joints
}

\author{
A. J. HARROLD \\ St. Mary's Hospital, London, W.9
}

When blood clots in a test-tube, fibrin strands form which enmesh the red blood cells and a clear serum is exuded as the clot retracts. When blood is shed into the cavity of a synovial joint it may coagulate in part, forming a relatively soft clot, but much of it remains apparently unaltered as a blood-like fluid. The red blood cells are not caught up in a fibrin network and there is no separation of a clear serum. This failure of normal coagulation within a joint has interested many writers (Jaffe, 1897; Vaubel, 1933; Jorpes, 1939; Ropes and Bauer, 1953). Astrup and Sjölin (1958) found that thromboplastic activity in human synovial and capsular tissues was very low when compared with almost all other tissues. The initiation of coagulation in an uninjured or slightly injured joint therefore depends on blood thromboplastins alone, the condition under which blood clots in vitro. The possibility of the existence of an intra-articular anticoagulant (antithrombin) has been investigated (Harrold, 1961), but no excess of this was found in haemarthrosis fluid when compared with plasma. Not only was the incoagulability of haemarthrosis fluid not corrected by the addition of excess thrombin, but by the use of specific antisera and of staphylococcal coagulase, it was shown that the failure to clot was caused by the absence of fibrinogen. The problem is thus reduced to a study of the fate of fibrinogen within the joint cavity.

Because of the persistence of fibrin deposits in the joints of rheumatoid arthritis, there has been much recent interest in the fibrinolytic powers of normal and diseased joint tissues (Bach Andersen and Gormsen, 1970; Caughey and Highton, 1967; Barnhart, Riddle, Bluhm, and Quintana, 1967). The elucidation of the mechanism whereby, in the otherwise normal joint, fibrinogen and fibrin are eliminated from the joint space has thus become of wider significance. Experiments in which citrated plasma was injected into the rabbit knee have shown that the fibrinogen level falls to zero in a little over 1 hour without the for- mation of an equivalent fibrin clot (Harrold, 1960). No fall occurs when heparin is added nor when the plasma is injected into the knee of a dead rabbit. It was suggested from this work that lysis of the fibrinogen was occurring in the joint cavity, a lysis occurring in competition with the clotting reaction catalysed by thrombin. The development of new techniques, particularly the estimation of fibrin degradation products (Merskey, Kleiner and Johnson, 1966), has allowed this hypothesis to be examined more closely and has required its modification. This paper reports studies on the fate of fibrinogen within synovial joints using both immunological and radioisotope techniques.

\section{Immunological studies}

\section{MATERIAL AND METHODS}

The tanned red cell haemagglutination inhibition immunoassay (TRCHII) of Merksey and others (1966) was employed. Tanned red cells are coated with fibrinogen by exposure to normal plasma. Addition of an antifibrinogen serum to a suspension of the cells in buffer causes prompt agglutination. This reaction is inhibited by previous exposure of the antiserum to a test solution containing fibrin degradation products. To estimate their concentration serial dilutions of the test solutions are prepared on a blood grouping plate. The end-point is taken as the greatest dilution sufficient to completely inhibit agglutination. It is compared with the inhibiting effect of serial dilutions of a standard plasma. Freshly tanned and sensitized red cells of rabbit or human group-O origin were used as appropriate. The antifibrinogen sera were made available through the courtesy of Prof. C. H. Lack and had been prepared in goats, using either rabbit fibrinogen alone or a complex of fibrinogen with chondroitin sulphate, the latter acting as an adjuvant and producing a more active antiserum. Samples of the chosen antiserum were adsorbed against equal volumes of either rabbit or human serum and the resulting precipitate discarded. The adsorbed sera were used for testing material of rabbit or human origin respectively. The TRCHII was applied to material from experimental haemarthroses in rabbits and to human haemarthrosis fluids of clinical origin. 


\section{$I_{125}$-labelled fibrinogen}

MATER I A L

Human fibrinogen labelled with $I_{125}$ was supplied by the Radiochemical Centre, Amersham, Bucks. In addition a supply of labelled rabbit fibrinogen was generously provided by Dr A.S. MacFarlane of the Clinical Research Centre, Northwick Park. Citrated rabbit plasma (2:8) was prepared and labelled with an appropriate quantity of the human or rabbit fibrinogen. Specimens were assayed in Perspex tubes using an Ekco type N.664B scintillation counter and automatic scaler. The thrombin coagulability of the label in the presence of rabbit plasma declined from 94 to 83 per cent. with the human material and from 80 to 78 per cent. with the rabbit fibrinogen during the course of the experiments.

\section{METHOD}

Labelled plasma, 2.0 to $2.5 \mathrm{ml}$., was injected into the knee of an anaesthetized rabbit. Samples of about 0.1 to $0.2 \mathrm{ml}$. were aspirated at 20 -minute intervals. Each sample was placed in a previously weighed tube and by reweighing the tube its exact size was measured. The total radioactivity was assayed and then thrombin added and the mixture incubated for $\mathbf{3 0}$ minutes. The clot was extracted, washed, and assayed for the coagulable portion of the radioactivity. At the end of the experiment, 80 to 90 minutes later the animal was killed and the joint widely opened, residual fluid and clot being collected and the cavity washed out with saline. The joint tissues were carefully excised and separately examined. In 22 experiments human fibrinogen was used, in twelve rabbit. There was no clear difference in the behaviour of the two labelled preparations. New Zealand Red rabbits, 3 to 12 months old, were used in all experiments

\section{The rabbit knee joint as an experimental model}

The rabbit knee joint, for all its convenience, has grave defects as a test-tube in that, in the first place injected fluid leaks from the joint, and secondly fibrinogen-free synovial fluid enters the joint during the course of the experiment. Dye studies have shown that fluid is lost into the upper leg along the tendon of tibialis anterior and is also rapidly absorbed through the synovial membrane itself. In twenty experiments the total loss of fluid during the 80 minutes of each experiment averaged 37 per cent., the range being 22 to 50 per cent. and the standard deviation 7.9 per cent.

When plasma containing labelled human albumin was injected into the rabbit knee joint, the concentration of the label fell by 28 per cent. and 30 per cent. during the following 80 minutes in two experiments. In two further experiments using heparinized plasma containing labelled fibrinogen, the falls in the level of coagulable label during 80 minutes were 20 per cent. and 31 per cent. These are considered to represent dilution by fresh synovial fluid.
A third difficulty arises when studying fibrinogen, for accidental initiation of the clotting mechanism may cause a portion of the fibrinogen under study to be inadvertently precipitated as fibrin. In fourteen experiments using labelled citrated plasma, fibrin clot recovered from the joint at the end of the experiment accounted for from 0 to 46 per cent. of the total injected, the average being 19 per cent. No such clot formation occurred when heparinized plasma was used.

\section{Results}

\section{EXPERIMENTAL HAEMARTHROSES}

Experiment 1 A 3-months-old female rabbit was anaesthetized with nembutal and ether. Blood was taken by cardiac needle puncture into a siliconed syringe and $3.0 \mathrm{ml}$. immediately injected into the right knee, a control sample being placed in a testtube in a water-bath at $37^{\circ} \mathrm{C}$. Half an hour later a similar injection was made into the left knee and a second control set up. One hour after the start of the experiment the animal was killed, the knees explored, and bloody fluid collected from each joint, any sof clots found being discarded. Both control samples had clotted well and clear serum was collected from these After the addition of a drop of epsilon-amino caproic acid $(0.025 \mathrm{ml}$. of a $100 \mathrm{mg}$./ml. solution) to prevent further proteolysis and a drop of thrombin $(1000 \mathrm{u} . / \mathrm{ml}$.) to all these specimens each was incubated for one hour and then spun. The supernatant fluids were tested for fibrin degradation products (FDP).

No excess of FDP was found in the 30 or 60 minute haemarthrosis fluids. The amount found in the 30-minute fluid and the control serum was equivalent to 0.2 per cent. of the original plasma fibrinogen, and in the 60 -minute fluid it was 0.4 per cent. There was thus no evidence of the liberation of FDP within the joint cavity.

Experiment 2 Autogenous citrated plasma was injected into the knee of an anaesthetized rabbit; 30 minutes later the fluid was aspirated and the fluid recovered divided into two portions. Epsilon-amino caproid acid (e.a.c.a.) was added to one while the other was clotted by incubation with thrombin and the serous fluid extracted. The two samples were then assayed by the TRCHII. The e.a.c.a.-treated portion gave a titre equivalent to 50 per cent. of the plasma but this was entirely attributable to the fibrinogen still remaining in the fluid, for the thrombin-treated portion produced a zero titre. The concentration of fibrinogen had thus fallen by about one half without the production of detectable free FDP. In two similar experiments, citrated plasma in a rabbit knee 
was examined 45 and 90 minutes after injection and no f.d.p. were demonstrable in either.

Further experiments in which plasma rich in FDP produced by incubation with varidase (streptokinasestreptodornase) was introduced into the rabbit knee produced no evidence of a major block to the detection of FDP by the immunoassay after the joint passage.

These experiments therefore indicated that the fall in fibrinogen level demonstrable in citrated plasma within the rabbit knee joint was not associated with a corresponding liberation of fibrin degradation products into the joint fluid.

\section{HUMAN HAEMARTHROSES}

Fluids from fourteen haemarthroses of clinical origin were available. E.a.c.a. was added to each on collection and the cells and debris were separated in a centrifuge. Specimens were collected from 8 hours to 5 days after the injury responsible. Each was stored at $4^{\circ} \mathrm{C}$ until testing. One had to be discarded because non-specific agglutination and haemolysis repeatedly prevented attempts at assay. Details of the results of the TRCHII in the others are set out in Table I. The level of FDP in these fluids ranged from 0.05 to 12 per cent. (average $4 \cdot 4$ ). In the ten cases in which titrations were done against a control plasma of known fibrinogen content, the levels of FDP were equivalent to from $0 \cdot 125$ to $26 \mathrm{mg}$. fibrinogen per $100 \mathrm{ml}$. There was no apparent relation between the level of FDP and the age of the haemarthrosis or the age of the patient, but the lowest level of FDP was found in a case of spontaneous haemarthrosis into an otherwise uninjured joint.

\section{I125-LABELLED FIBRINOGEN}

The results of thirteen experiments are shown in Fig. 1. The amount of label in the joint plasmas fell on average to 16 per cent. of its original level in $80 \mathrm{~min}$ utes. The remaining radioactivity in the joint fluid-

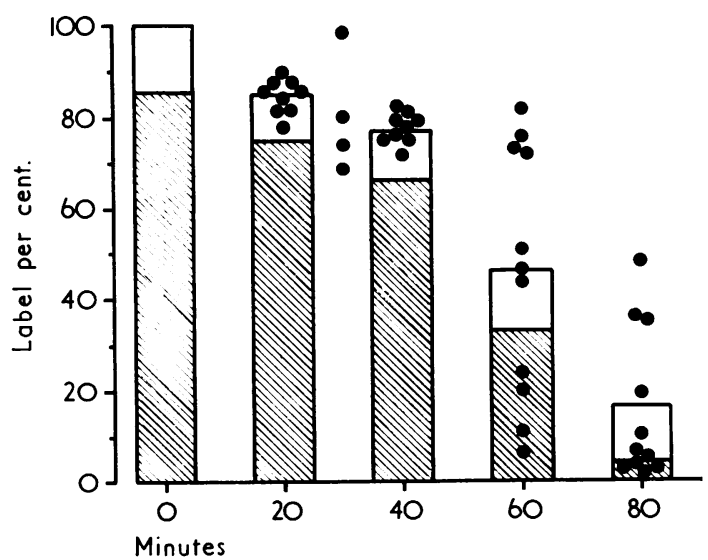

FIG. 1 Serial estimations of activity of citrate plasma containing $I_{125}$ fibrinogen in the rabbit knee joint (thirteen experiments). Individual assays are indicated. Superimposed histogram shows mean level of radioactivity every 20 min. Shaded portions indicate proportion coagulable with thrombin.

was less coagulable by thrombin than before introduction into the joint but the coagulability varied and showed some relation to the total remaining amount of label. Where this total exceeded 10 per cent. 67 per cent. of the label was coagulable, whereas when the total was less than 10 per cent. only $5 \cdot 6$ per cent. of it was coagulable with thrombin. These results showed that much of the remaining radioactivity was associated with incoagulable label. The experiments thus confirmed the earlier findings that the fibrinogen level of the joint plasma falls to zero or nearly so within $1 \frac{1}{2}$ hours without the formation of an equivalent amount of fibrin clot. They also show that the fall in fibrinogen was not associated with the release into the joint fluid of a corresponding quantity of labelled split products. The possibility that fibrin degradation products might be immediately absorbed from the

Table I Quantity of fibrin degradation products in human haemarthrosis fluids

\begin{tabular}{|c|c|c|c|c|c|c|}
\hline \multirow{2}{*}{$\begin{array}{l}\text { Fluid } \\
\text { number }\end{array}$} & \multirow[t]{2}{*}{ Sex } & \multirow{2}{*}{$\begin{array}{l}\text { Age } \\
\text { (yrs) }\end{array}$} & \multirow[t]{2}{*}{ Injury } & \multirow{2}{*}{$\begin{array}{l}\text { Duration of } \\
\text { haemarthrosis } \\
\text { (hrs) }\end{array}$} & \multicolumn{2}{|c|}{ FDP level } \\
\hline & & & & & per cent. & $m g . / 100 \mathrm{ml}$. \\
\hline $\begin{array}{r}1 \\
2 \\
3 \\
4 \\
5 \\
6 \\
7 \\
8 \\
9 \\
10 \\
11 \\
12 \\
13\end{array}$ & $\begin{array}{l}\mathbf{F} \\
\mathbf{M} \\
\mathbf{M} \\
\mathbf{F} \\
\mathbf{M} \\
\mathbf{M} \\
\mathbf{F} \\
\mathbf{M} \\
\mathbf{M} \\
\mathbf{M} \\
\mathbf{M} \\
\mathbf{M} \\
\mathbf{M}\end{array}$ & $\begin{array}{r}6 \\
25 \\
25 \\
79 \\
89 \\
35 \\
69 \\
50 \\
82 \\
17 \\
7 \\
5 \\
65\end{array}$ & $\begin{array}{l}\text { Fractured tibial spine } \\
\text { Internal derangement of knee } \\
\text { Fractured tibial condyle } \\
\text { Fractured neck of femur } \\
\text { Fractured neck of femur } \\
\text { Fractured patella } \\
\text { Spontaneous haemarthrosis of knee } \\
\text { Fractured patella } \\
\text { Fractured neck of femur } \\
\text { Fractured tibial condyle } \\
\text { Fractured tibial spine } \\
\text { Fractured tibial spine } \\
\text { Fractured tibial condyle }\end{array}$ & $\begin{array}{r}48 \\
65 \\
72 \\
72 \\
60 \\
36 \\
8 \\
20 \\
30 \\
20 \\
48 \\
48 \\
48\end{array}$ & $\begin{array}{l}6 \cdot 25 \\
6 \cdot 25 \\
12 \cdot 5 \\
1 \cdot 5 \\
6 \cdot 25 \\
3 \cdot 0 \\
0 \cdot 05 \\
\text { Non-spec } \\
0 \cdot 8 \\
0 \cdot 8 \\
3 \cdot 0 \\
12 \cdot 0 \\
3 \cdot 0\end{array}$ & $\begin{array}{l}13 \\
13 \\
26 \\
3 \\
13 \\
6 \\
0 \cdot 125 \\
\text { agglutination } \\
2 \cdot 0 \\
2 \cdot 0 \\
7 \cdot 5 \\
-\end{array}$ \\
\hline
\end{tabular}


joint was examined in a further experiment in which plasma containing labelled fibrinogen was incubated with varidase to produce a fluid rich in labelled split products. The rate of fall in the level of activity of this fluid when injected into the rabbit knee is shown in Fig. 2. After a brief steep fall the rate of loss was for a time parallel with the rate of loss of fibrinogen from the opposite control knee.

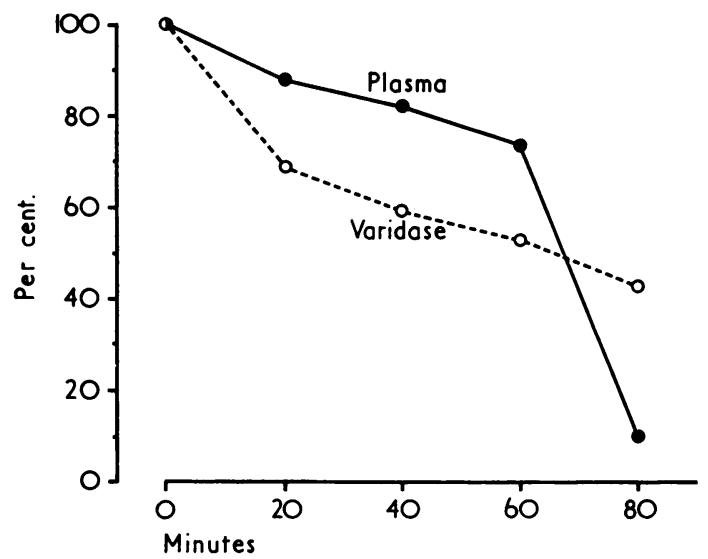

FIG. 2 Radioactivity assays of citrate plasma and of varidase serum injected into opposite knees of the same rabbit. Note parallel rates of loss of activity from the two knees between 20 and 60 min.

The fall of fibrinogen level noted in citrated plasma injected into the rabbit knee was much reduced when heparin $(5 \mathrm{u}$./ $/ \mathrm{ml}$.) was added and when the experiment was done on the recently dead animal (Fig. 3).

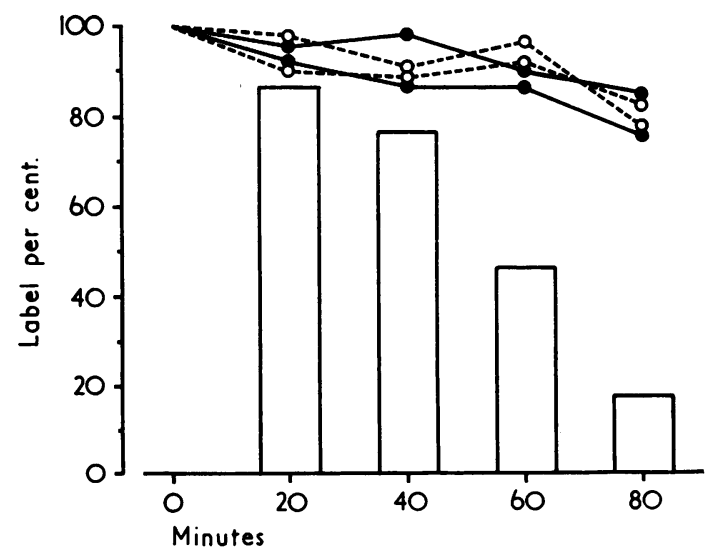

FIG. 3 Radioactivity assays of (a) heparin plasma in the living rabbit's knee (solid dots), and (b) citrate plasma in the dead rabbit's knee (open dots). Results of four experiments. The histogram is that in Fig. 1 and indicates the mean levels of activity with citrate plasma in the living animal.
EXAMINATION OF THE SYNOVIAL MEMBRANE Synovial membrane from the rabbit joints injected with labelled plasma was carefully excised, weighed, and assayed for radioactivity. In two experiments comparison was made with the synovial tissues of the opposite knee which had received as a control an identical volume of serum prepared from the same labelled plasma. Label in the synovial tissues of the control knee represented that derived from the uncoagulable portion of the original labelled plasma. Excess label in the tissues of the test knee represented label derived from the fibrinogen in that joint. The results of these two experiments are shown in Table II.

Table II Radioactivity of synovial membrane from rabbit knees after injecting labelled plasma into one and the derived serum into the opposite control joint. Two experiments are shown: (a) labelled human fibrinogen (b) labelled rabbit fibrinogen

\begin{tabular}{|c|c|c|}
\hline Fibrinogen & (a) Human & (b) Rabbit \\
\hline $\begin{array}{l}\text { Total label injected } \\
\text { Total coagulable label } \\
\text { (fibrinogen) injected }\end{array}$ & $\begin{array}{l}9 \cdot 94 \\
9 \cdot 1\end{array}$ & $\begin{array}{l}1.25 \\
0.97\end{array}$ \\
\hline $\begin{array}{l}\text { Test synovial membrane } \\
\text { Control synovial membrane } \\
\text { Test minus control } \\
\text { Fibrinogen in synovial }\end{array}$ & $\begin{array}{l}2 \cdot 2 \\
0 \cdot 02 \\
2 \cdot 18 \\
24\end{array}$ & $\begin{array}{l}0 \cdot 21 \\
0 \cdot 023 \\
0 \cdot 187 \\
19\end{array}$ \\
\hline
\end{tabular}

The units represent millions of counts $/ 100 \mathrm{sec}$.

The synovial membrane showed activity equivalent to 24 per cent. of the total fibrinogen injected when the human preparation was used and 19 per cent. with labelled rabbit fibrinogen. In thirteen further experiments the proportion of the total label injected that was later indentifiable in the synovial membrane excised varied widely and rather unpredictably from 3.1 to 28 per cent. Activity was highest in the thin tissue lining the suprapatellar pouch and posterior recesses and lowest per unit weight in the fat pads. Other joint tissues, cartilage, menisci, and bone contained less than $0 \cdot 2$ per cent. of the total label.

EXAMINATION OF THE PERIPHERAL BLOOD Only a limited study of the circulating blood was carried out. Radioactivity was demonstrable within 20 minutes of the start of the experiments and steadily rose thereafter. The label was to a great extent not precipitable by trichloracetic acid, that is, it was not protein bound, but no systematic study has been undertaken to determine to what extent it was derived from the labelled fibrinogen or from the uncoagulable portion.

\section{LOSS OF FIBRINOGEN FROM THE RABBIT KNEE} JOINTS

If the total radioactive label injected into the joint is compared with the total of label recovered in the 
aspirated samples, residual fluid, washings, and clot from the joint, an estimate can be made of the total label that has leaked out of or been absorbed from the joint. In eleven experiments using citrated plasma, while the loss of fluid from the knees averaged 40 per cent. (range 30 to 50), the loss of radioactive label averaged 60 per cent. (range 38 to 72 ) and this in spite of some of the label being precipitated as fibrin clot and not therefore available for absorption or leakage from the joint. If one considers only the coagulable label, the labelled fibrinogen, and excludes from the calculations that part lost as clot, of the residue, on average 80 per cent. of the total injected, in the eleven experiments 62 to 89 per cent. (mean 75, standard deviation 13) of this available fibrinogen was lost or absorbed from the joint. The rest appeared in the aspirated samples and residual fluid and washings. In two experiments modified by omission of the intermediate aspirations 86 and 90 per cent. of the available fibrinogen was so lost or absorbed from the joint.

Estimation of the loss of coagulable label from a joint containing heparinized plasma produced in two experiments figures of 56 and 53 per cent. The loss from citrated plasma in the opposite control knees was 78 and 83 per cent. respectively (Table III). If the loss with heparinized plasma is compared with that with the series of fourteen experiments using citrated plasma, the difference is statistically significant at a level of $\mathbf{P}<0.01$. Similarly, in two experiments with animals whose circulation had been stopped immediately before injecting the plasma, the fibrinogen loss was only 48 and 43 per cent.

Table III Loss of fibrinogen from heparin plasmatwo experiments. Control experiments using citrate plasma were done on the opposite knees

\begin{tabular}{|c|c|c|}
\hline Experiment & 1 & 2 \\
\hline $\begin{array}{l}\text { Heparin plasma } \\
\text { Fibrinogen loss } \\
\text { Fluid loss }\end{array}$ & $\begin{array}{l}56 \% \\
25 \%\end{array}$ & $\begin{array}{l}53 \% \\
42 \%\end{array}$ \\
\hline $\begin{array}{l}\text { Citrate plasma } \\
\text { Fibrinogen loss } \\
\text { Fluid loss }\end{array}$ & $28 \%$ & $83 \%$ \\
\hline
\end{tabular}

\section{Discussion}

The present study has shown that fibrinogen injected into the knee joint of the rabbit disappears rapidly and almost completely. Its disappearance cannot be accounted for by the small amount of fibrin clot formed or by the appearance of free fibrin degradation products in the joint fluid. Some loss can be accounted for by the leakage from the joint space along the tendon of tibialis anterior and by a probable dilutional effect by the entry of new, fibrinogen-free synovial fluid into the joint. These factors alone could not account for the marked fall in fibrinogen levels recorded. Experiments with fibrinogen labelled with $I_{125}$ showed that up to 24 per cent. of the fibrinogen label injected into the joint space could be found in the excised synovial membrane, suggesting that this tissue may be a route for the elimination or absorption of fibrinogen from the joint. The effects of circulatory arrest suggest that the fibrinogen is carried away in the blood stream and implies that it has diffused through the normally impermeable capillary wall, presumably as degradation products. Heparin would not normally be expected to affect such loss by simple diffusion, but it must be remembered that as well as inhibiting the action of thrombin it is an inhibitor of many other proteases. If its action in preserving the fibrinogen level of the joint plasma were by virtue of its anticoagulant effect alone, one would expect, because of the sustained higher fibrinogen levels, a greater total diffusion of fibrinogen from the joint than that observed with citrated plasma which on this hypothesis less effectively prevented coagulation and in consequence allowed a considerable fall in fibrinogen level. In fact the opposite was observed. Heparin, while maintaining the plasma fibrinogen level, at the same time decreased the total loss from the joint. It is suggested that the heparin blocked a system in the synovial membrane which facilitates the absorption of fibrinogen by proteolytic breakdown.

\section{Summary}

Studies by immunological methods and radioisotope labelling are reported which show that, in both experimental and clinical haemarthroses, the disappearance of fibrinogen from the joint contents is not associated with the liberation of a corresponding quantity of fibrin degradation products. After the injection of plasma into the rabbit knee radioactive label from the labelled fibrinogen was identifiable in significant quantities in the synovial membrane. Evidence is put forward for the selective absorption of fibrinogen from the joint cavity.

It is a pleasure to acknowledge the generous help and encouragement given by the Institute of Orthopaedics and by Prof. C. H. Lack. Prof. P. L. Mollison first called my attention to the methods used and Dr. W. R. Pitney gave valuable technical advice. I am indebted to Dr. A. S. MacFarlane for supplies of labelled rabbit fibrinogen. The expenses were in part defrayed by a grant from the Board of Governors of St. Mary's Hospital, London, W.2. Dr. B. P. Harrold gave much appreciated editorial advice. 


\section{References}

Astrup, T., AND Suölin, K. E. (1958) Proc. Soc. exp. Biol. (N.Y.), 97, 852 (Thromboplastic and fibrinolytic activity of human synovial membrane and fibrous capsular tissue)

Bach ANDERsen, R., AND GoRmSEn, J. (1970) Ann. rheum. Dis., 29, 287 (Fibrinolytic and fibrin stabilizing activity of synovial membrane)

Barnhart, M. I., RidDle, J. M., Bluhm, G. B., ANd Quintana, C. (1967) Ibid., 26, 206 (Fibrin promotion and lysis in arthritic joints)

Caughey, D. E., and Highton, T. C. (1967) Ibid., 26, 297 (Components of the fibrinolytic system in synovial joints)

HARROLD, A. J. (1960) Nature (Lond.), 186, 1057 (Fibrinogenolysis in joints)

(1961) J. clin. Path., 14, 305 (The defect of blood coagulation in joints)

JAFFe, A. (1897) Arch. klin. Chir., 54, 69 (Ueber die Veränderungen der Synovialmembran bei Berühring mit Blut)

JORPES, J. E. (1939) 'Heparin'. Oxford University Press, London

MERSKEY, C., KLeINER, G. J., AND JohnSON, A. J. (1966) Blood, 28, 1 (Quantitative estimation of split products of fibrinogen in human serum: relation to diagnosis and treatment)

Ropes, M. W., AND BAUER, W. (1953) 'Synovial Fluid Changes in Joint Diseases.' Harvard University Press, Cambridge, Mass.

VAUBEL, E. (1933) J. exp. Med., 58, 63, 85 (Form and function of synovial cells in tissue cultures) 